\title{
Valorization of Bauxite Residue: A Challenge that Leads to a Mentality Shift and Eventually Innovation
}

\author{
Yiannis Pontikes
}

\section{Extended Abstract}

Bauxite residue, BR, produced during the Bayer process continues to be a challenge for the alumina refineries in terms of management, with increasingly large amounts being produced each year, on top of the billions of tonnes stored around the world. This presentation will give an overview of the efforts, taking place predominantly in Europe, that aspire to address the above challenge. Multiple universities and research institutes partner together and liaise with the industry to drive projects in several directions. The data to be presented cover research projects and new research findings, including processes, that have a high potential to deliver pragmatic innovations.

With respect to research projects, three cases will be presented: two competitive projects, both aiming to upscale processes at a higher technology readiness level, and that of an academic project, where $15 \mathrm{PhD}$ students from all over Europe worked on bauxite residue. Emphasis will be placed on the highlights and deliverables of each project, achieved already or expected.

In terms of research efforts, the presented work will be grouped over three domains: that of base metal recovery (mainly iron and aluminium), rare earth elements recovery (predominantly Scandium) and that of novel iron-rich binders. The latter topic will be extensively covered during the presentation in line with their perceived high potential in terms of volume and feasibility. Effectively, these new materials can accommodate substantial volumes of BR (up to $95 \mathrm{wt} \%$ ) and can be produced today, in the premises of an alumina refinery. Examples of how such a process looks like and data on material's properties will be also presented. Moreover, areas of sensitivity like levels of natural radioactivity, as well as market and perception barriers, will be discussed as a sine qua non condition for any BR reuse initiative to come to fruition.

The presentation will finally try to communicate the over-arching "big picture". Indeed, the work in each research domain aspires to lead to more sophisticated processes, but at the same time it is possible that these "process units" can function in a complementary manner, leading to a near-zero waste flow sheet that can be put in operation. In the latter case, the financial aspects become more attractive, and in order to achieve the target of profitability, an existing industrial symbiosis network, or one to-be-created, will facilitate this transition. In that scheme, the needs of the industrial and social matrix are met and BR utilization is a more resilient business (and ecological) proposal.

Y. Pontikes $(\bowtie)$

Department of Materials Engineering, KU Leuven, Leuven,

Belgium

e-mail: yiannis.pontikes@kuleuven.be 